\title{
Olivares y LA ESCENIFICACIÓN DEL PODER A TRAVÉS DE LA ARQUITECTURA. UN LIENZO DE JUAN DE LA CORTE EN Pollock House (H. 1635)
}

\author{
InMaculada Rodríguez, Víctor Mínguez \\ Universitat Jaume I
}

Resumen: La colección pictórica de la Pollock House de Glasgow alberga un lienzo atribuido a Juan de la Corte, pintor de corte de Felipe IV. El lienzo representa una fantástica arquitectura de columnas salomónicas, que cobija a cuatro personajes cortesanos. A partir del análisis de los personajes, de la arquitectura y de los referentes literarios se argumenta su atribución al pintor de origen flamenco y su posible simbolismo vinculado con el Palacio del Buen Retiro como nuevo Templo de Salomón.

Palabras clave: Juan de la Corte, Felipe IV, Palacio del Buen Retiro, Templo de Salomón.

ABSTRACT: The Pollock House' collection of paintings in Glasgow hosts a canvas attributed to Juan de la Corte, Phillip IV's court painter. The canvas depicts a fantastic architecture of Solomonic columns, which is home to four courtiers' characters. Based on the analysis of the characters, of architecture and of literary references, the authors argue its attribution to the painter of Flemish origin and its possible symbolism associated with the Buen Retiro Palace as a new temple of Solomon.

Keywords: Juan de la Corte, Phillip IV, Buen Retiro Palace, Solomon's Temple. 


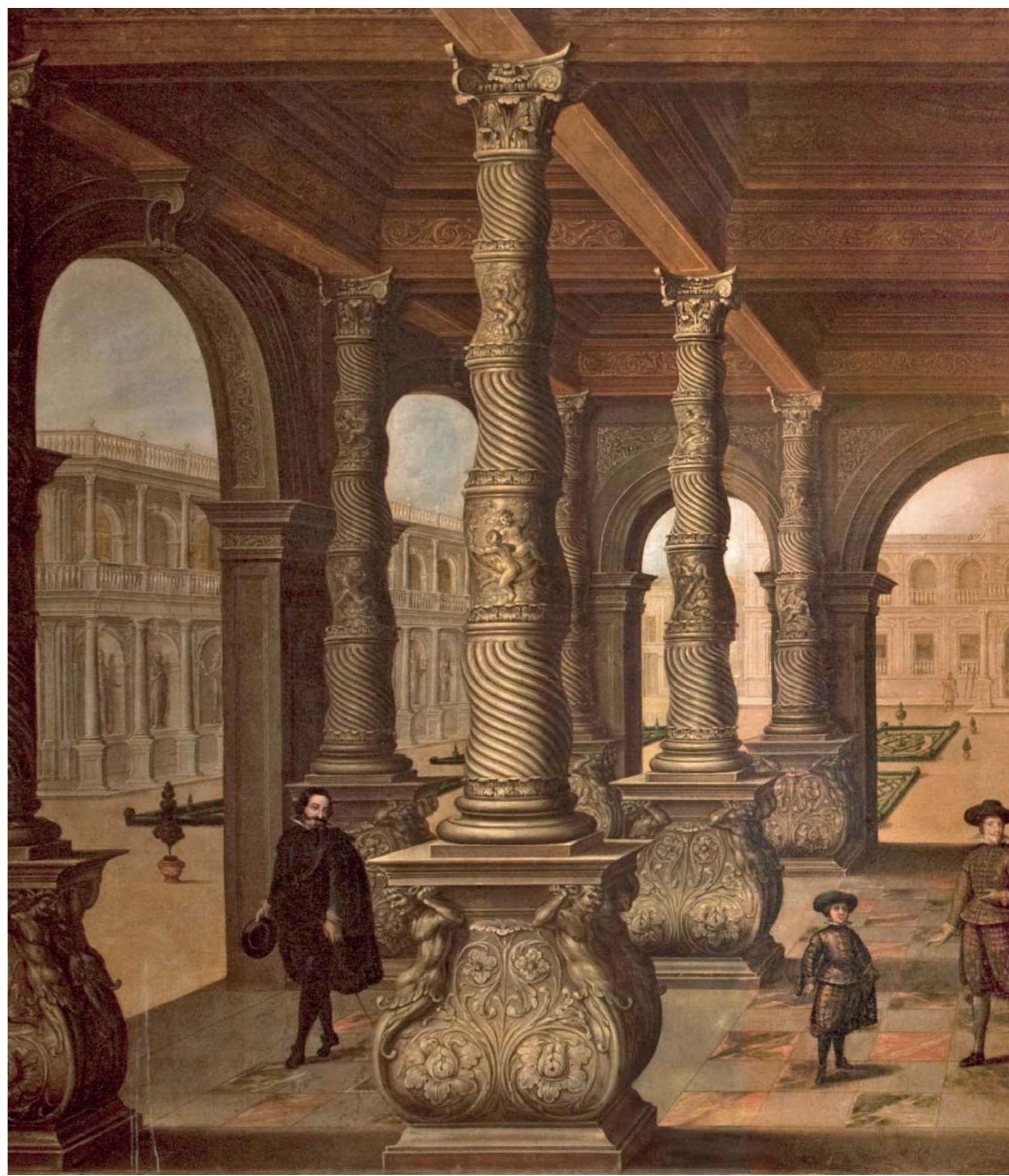

Fig. 1. JUAN DE LA CORTE, atribuido, Philip IV and his Queen in a Colonnade, Pollock House, Glasgow 


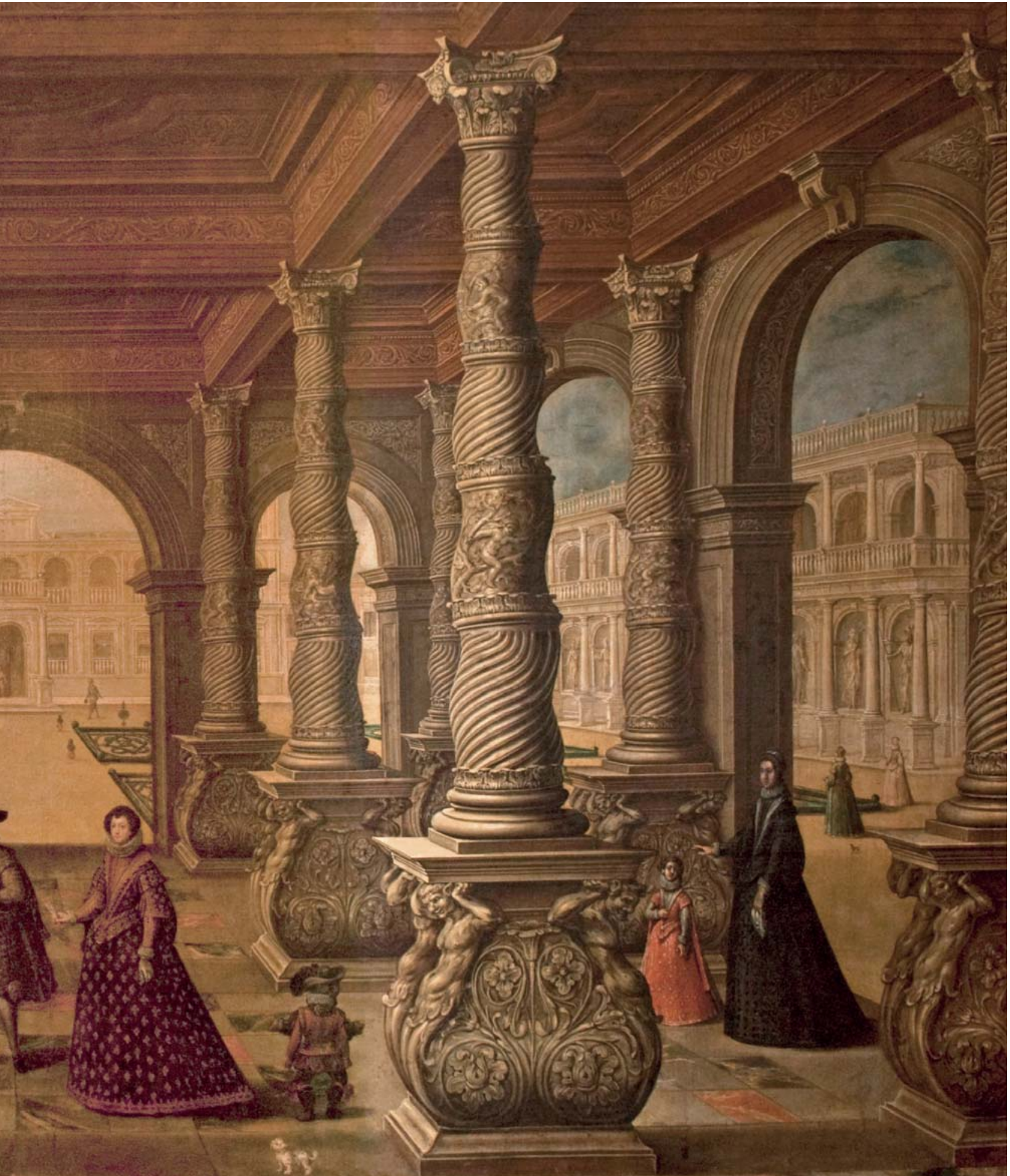


T a colección pictórica de la Pollock House (Glasgow), reunida por Sir John Stirling Maxwell, cuenta con excelentes muestras del arte español del Siglo de Oro [Fig. 2]. Una de estas pinturas ha despertado nuestro interés. La Cedar Room, o sala de cedro, creada en 1929 como estancia para fumar anexa al comedor y panelada con madera procedente del norte de Borneo, contiene, además de algunas pinturas de William Blake, un óleo sobre lienzo de gran formato (181,1 x 303,8 cm), catalogado como Philip IV and his Queen in a Colonnade, considerado tradicionalmente de la escuela de Velázquez [Fig. 1]. ${ }^{1}$ Sin embargo, el lienzo fue atribuido en 1981 a Juan de la Corte (hacia 15851650) por Antonio Martínez Ripoll, tanto por su estilo, más característico de la pintura flamenca, como por su cronología. ${ }^{2}$ Esta impresionante y casi desconocida pintura nos plantea diversas dudas. Si admitimos que el monarca es Felipe IV, ¿de cuál de sus dos esposas se trata?, ¿quiénes son los restantes personajes?, ¿dónde transcurre la acción?, ¿qué representa la pintura?

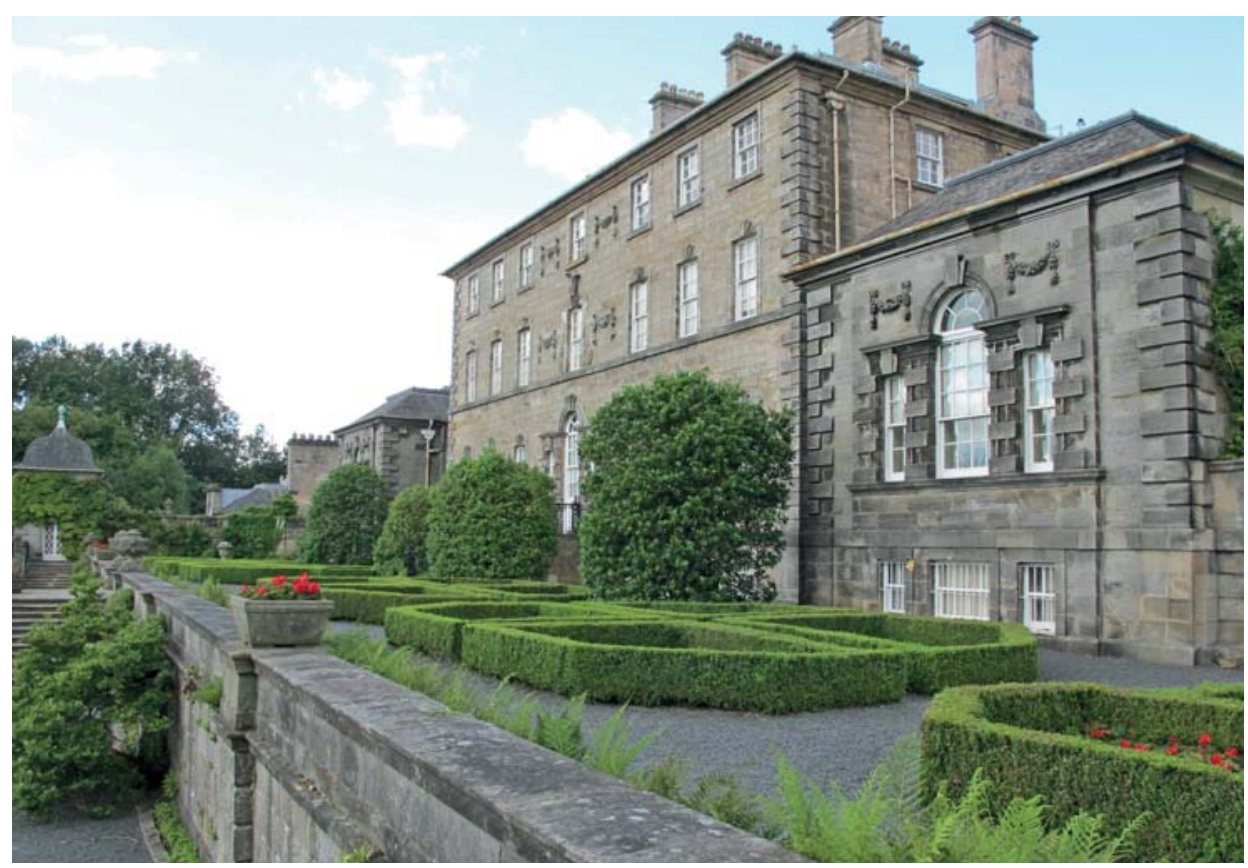

Fig. 2. Pollock House, Glasgow

1. Sir William Stirling-Maxwell compró la obra en la venta del general George G. Meade en 1851, el famoso vencedor de la batalla de Gettysburg, nacido en Cádiz.

2. Caw, J. L., Catalogue of Pictures at Pollok House, Glasgow, 1936, p. 33, n. 52, lo atribuyó a la escuela de Velázquez, aunque más probablemente a un pintor flamenco del siglo xviI ; en The Stirling Maxwell Collection Pollok House, Corporation of Glasgow: Museum and Art Galleries Department, c. 1967, p. 63, n. ${ }^{\circ} 71$, es catalogado como de la escuela de Velázquez, así como en MACARTNEY, H., «La colección Stirling Maxwell en Pollok House, Glasgow», Goya, vol. 291, noviembre - diciembre 2002, pp. 349-50, 356, ill. 14. Martínez Ripoll lo incluyó entre las obras de Juan de la Corte en «Juan de la Corte. Un pintor flamenco en el Madrid de Calderón», Goya, n. ${ }^{\circ} 161$ (1981), pp. 312-320. Sin embargo, Angulo Î́niguez y Pérez Sánchez rechazaron su autoría. 


\section{La familia de Felipe IV y del Conde-duQue en el Buen Retiro}

Las primeras dos cuestiones son fáciles de contestar. La juventud del monarca, las facciones de la reina y la indumentaria que portan ambos nos remite al matrimonio formado por Felipe IV e Isabel de Borbón, su primera esposa. Les acompaña un niño de entre cinco y seis años, en el que es fácil reconocer asimismo al príncipe Baltasar Carlos, y aparece también un bufón de espaldas. A ambos lados de este grupo principal, descubrimos en los intercolumnios laterales otras figuras. A la izquierda el poderoso valido del monarca, el condeduque de Olivares; a la derecha, la duquesa, doña Inés de Zúñiga, acompañada de la hija del matrimonio. La presumible edad de los personajes, especialmente del príncipe Baltasar Carlos (1629-1646), nos permite situar la escena representada en torno a 1635 [Fig. 3]. Esta fecha nos facilita interpretar la fantasía arquitectónica que envuelve a los personajes. El gran patio palaciego y columnado que enmarca la escena, creando un hermoso y bien trazado espacio en perspectiva, no corresponde como es obvio a ninguno de los palacios madrileños usados por Felipe IV. No es el Alcázar, ni El Escorial, ni El Pardo, ni el Buen Retiro. Sin embargo, cuando se realizó la pintura que nos ocupa, este último palacio estaba en construcción. Proyectado en 1629 como anexo a un monasterio jerónimo, su fabricación -dirigida inicialmente por Juan Bautista Crescenzi y tras su muerte en 1635 por Alonso Carbonel- no se inició hasta 1630, para concluir una década más tarde. En 1632 Olivares dio un giro al proyecto, ideando un gran palacio con una segunda plaza destinada a festejos -la Plaza Grande ${ }^{3}$ iniciada en 1634-, además de amplios jardines, estanques, un canal navegable y ermitas. ${ }^{4}$ No tenemos dudas de que la pintura de Pollock House, realizada casi con seguridad en los primeros años de la tercera década del siglo XVII, fantasea sobre las posibilidades de este gran conjunto, un palacio que verdaderamente fue construido sin un plan director inicial.

Al tratarse de una fantasía sobre el Palacio del Buen Retiro, se entiende perfectamente la presencia en el lienzo del conde-duque de Olivares, verdadero promotor de la construcción del palacio. Como señaló Andrés Úbeda de los Cobos, quizá Olivares discurrió los pormenores de la construcción con el rey, quizá el conde-duque fuera su único arquitecto e informase al rey de tanto en tanto. ${ }^{5}$ De hecho, la rapidez e improvisación con que se ideó todo por parte de Olivares despertó numerosas críticas y chanzas, como la del embajador florentino que calificó la idea de Olivares como una «gran fattura tutta di sua mano, et capriccio». 6

3. Jonathan Brown, «El Palacio del Buen Retiro: un teatro de las artes», en Úbeda DE Los Cobos (ed.), El Palacio del Rey Planeta, p. 70.

4. Mercedes Simal López, «El Palacio del Buen Retiro (1633-1648)», Librosdelacorte.es, nº 5, otoñoinvierno, 2012, p. 126.

5. Andrés Úbeda de los Cobos, «La decoración pictórica del Palacio del Buen Retiro», en Úbeda DE Los Совоs (ed.), El Palacio del Rey Planeta. Felipe IV y el Buen Retiro, Museo Nacional del Prado, 2005, p. 22.

6. Crf. En Simal López, «El Palacio del Buen Retiro», p. 126. 


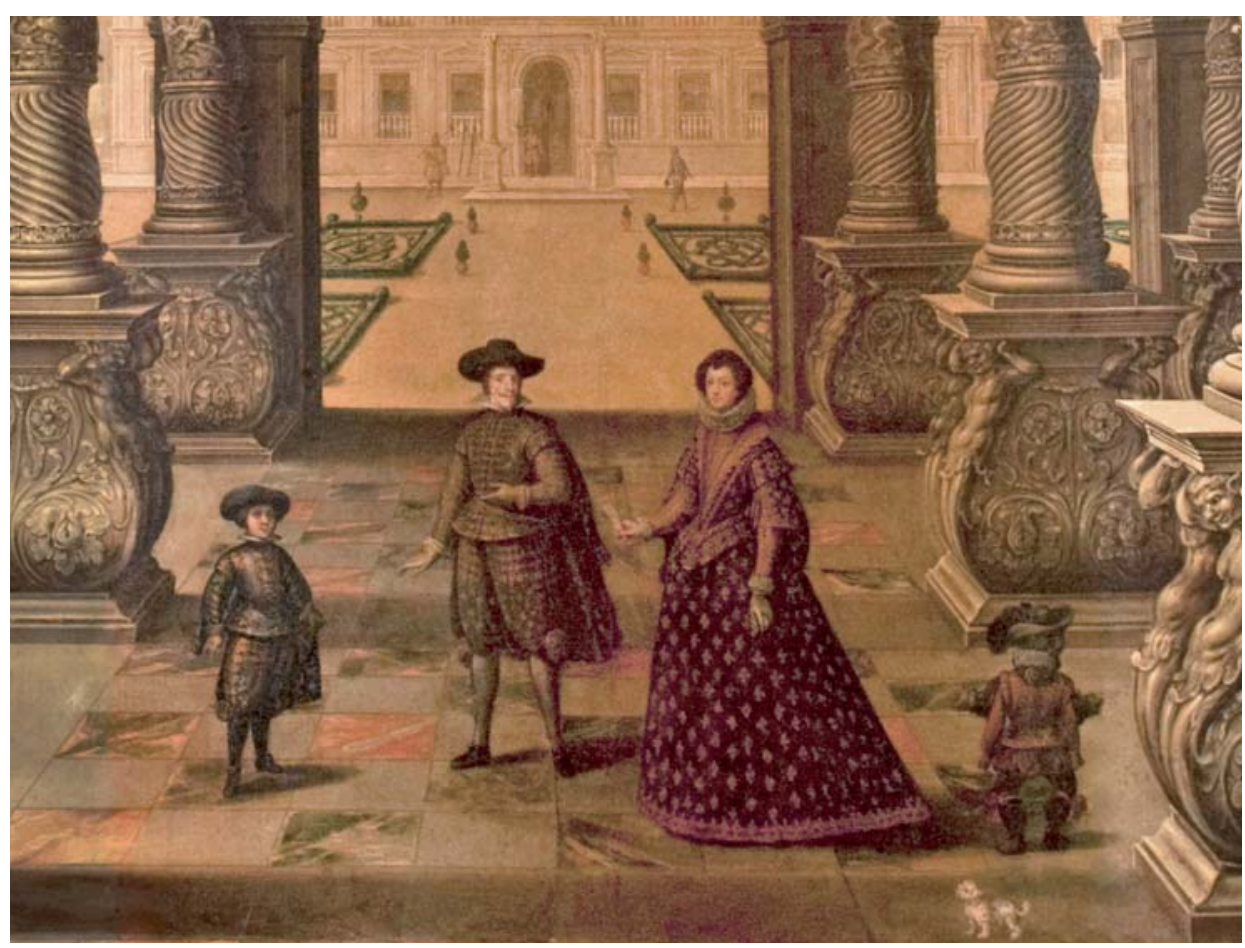

Fig. 3. Detalle, JuAn De La Corte, atribuido, Philip IV and his Queen in a Colonnade, Pollock House, Glasgow

La tercera de la preguntas, dónde transcurre la acción, es más difícil de resolver, dada la escasez de imágenes del Palacio realizadas en el periodo. El caso es que la escena se sitúa en un gran patio, que según Martínez Ripoll era el que se ubicaba entre el Coliseo y la Sala de Baile del Casón, y que según él fue donde luego se situó la escultura ecuestre de Felipe IV realizada por Tacca. ${ }^{7}$ Martínez Ripoll, que tiene el mérito de haber reparado primero que nadie en el interés de esta pintura, se confundió sin embargo. Este espacio se cerró en realidad en 1637, cuando se comenzó la edificación de los dos edificios citados. En nuestra opinión, se trataría en realidad del Jardín de la Reina, localizado entre el cuarto de la reina y el cuarto del príncipe. Un jardín más íntimo reservado a la vida familiar, cuya estructura, amplitud y sus jardines a la italiana parecen corresponderse en un alto grado con lo representado en el lienzo de Pollock House, y quizá la pintura sea un proyecto ideado por Olivares para él mismo, trasladado a la tela por Juan de la Corte. En este jardín fue en el que se instaló en 1642 la estatua ecuestre de Felipe IV realizada por Pietro Tacca en Florencia, incluso podríamos afirmar que en el mismo

7. Martínez Ripoll, «Juan de la Corte», p. 320. 
emplazamiento de nuestro espectacular baldaquino. El plano de Madrid de Teixeira de 1656 (Museo Municipal de Madrid) también nos permite ver en el detalle del Palacio del Buen Retiro una gran correspondencia entre ambos espacios. Sin embargo, este jardín queda oculto en el lienzo de Jusepe Leonardo de 1636-1637 (Palacio Real, Madrid) que recoge la perspectiva caballera del Buen Retiro.

Antes de intentar responder a la cuarta de nuestras dudas, qué representa la pintura, vamos a intentar abordar la cuestión de su autoría, que atribuimos a Juan de la Corte o a alguien del círculo madrileño de pintores de perspectivas del segundo tercio del siglo XVII.

\section{JuAN DE LA CORTE y LA PINTURA CORTESANA DE PERSPECTIVAS ARQUITECTÓNICAS}

Juan de la Corte es un pintor sobre el que todavía tenemos muchas incógnitas. Él mismo declaró haber nacido en la ciudad de Amberes y allí recibió su primera formación. ${ }^{8}$ Desde 1610-1613 ya aparece establecido en España, con una sólida preparación, y su producción se extiende hasta 1650 aproximadamente, fecha en torno a la que debió morir. Uno de sus hijos fue también pintor con el mismo nombre, y seguramente sería el pintor con ese nombre fallecido en $1662,{ }^{9}$ cuya fecha sin embargo sigue apareciendo en la bibliografía como la de la muerte del padre. Esto ha llevado a que no sepamos a ciencia cierta qué obras deben de atribuirse a cada cual. De hecho, según Pérez Sánchez fue el hijo el que solicitó en 1627 la plaza de Bartolomé González, trabajando para la corte como pintor del rey, aunque Palomino lo consideraba de menor habilidad. ${ }^{10}$ Sabemos que Juan de la Corte era especialista en retratos -de los que no se conserva ninguno-, además de pintor de arquitecturas, batallas y países, con carácter decorativo. Son famosos sus lienzos plasmando las fiestas celebradas en Madrid con motivo del posible compromiso entre Carlos I de Inglaterra y María Ana de Austria: Fiesta en la Plaza Mayor de Madrid (Museo Municipal de Madrid) de hacia 1623 [Fig. 4].

Sus lienzos formaron parte de la decoración de muchos palacios de la nobleza española, representando frecuentemente temas épicos, como varias series con las Historias de la guerra de Troya (duque de Medinaceli, conde de Villalcázar), Empresas de Carlos V (conde de Atalaya), las Victorias de Carlos $V$ (hoy en la embajada de España en Londres), e Historias de Carlos $V$ (conde de Revillagigedo y Museo de Santa Cruz en Toledo); también una Planta del Escorial (hoy perdido) y escenas bíblicas. Asimismo, había doce

8. Martínez Ripoll, «Juan de la Corte», p. 312.

9. Duncan KinheAd, «El testamento del pintor Juan de la Corte», Boletín de estudios de Arte y Arqueología, pp. 461-462.

10. Alfonso E. Pérez Sánchez, Pintura barroca en España (1600-1750), Cátedra, Madrid, 2010, p. 114. 


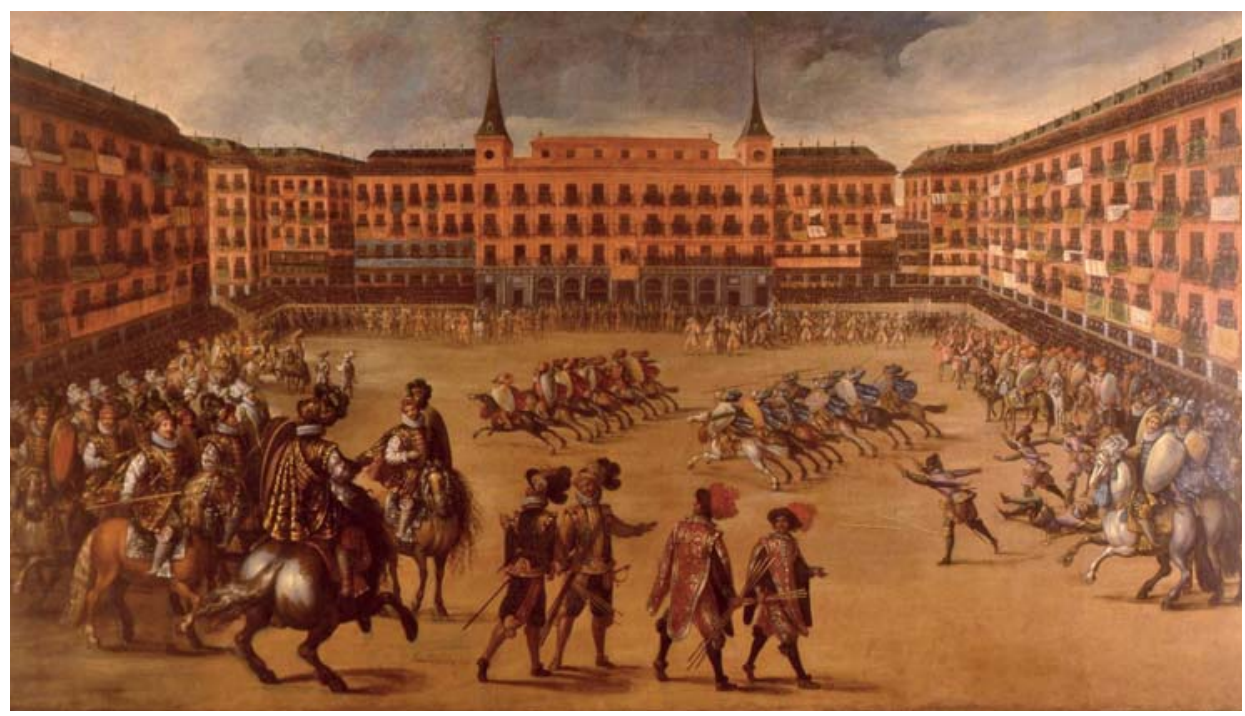

Fig. 4. Juan de la Corte, Fiesta en la Plaza Mayor de Madrid, hacia 1623, Museo Municipal de Madrid

lienzos suyos en el Alcázar de Madrid, con diferentes historias sin tema conocido. ${ }^{11}$ Es notable en sus lienzos de perspectivas arquitectónicas la influencia de Vredeman de Vries y de Sebastian Vranck. También hay cierta cercanía entre Juan de la Corte y David Vinckenboons o Hendrick van Steenwijck y sus escenas galantes en escenarios arquitectónicos y jardinísticos. Pero más notable y sugerente es la relación entre Juan de la Corte y Louis de Caulery. ${ }^{12}$ Pérez Sánchez ya señaló la semejanza en obras como el Carnaval sobre el hielo de Caulery (Hamburger Kunsthalle). Pero otro ejemplo en el que existe una notable semejanza, es la propuesta de los dos primeros cuerpos del Mausoleo de Halicarnaso en la serie de las Maravillas del mundo de Caulery (Palacio de Aranjuez) con los dos cuerpos del supuesto patio del palacio del Buen Retiro, donde se sitúa el escenario [Fig. 5]. Un lienzo inspirado a su vez en el grabado de Maerten van Heemskerck de la serie de las maravillas. En ambas vemos un primer nivel con hornacinas con esculturas y un segundo con hornacinas ciegas. Ambos pintores eran de Amberes, ambos trabajaban allí hacia principios del siglo XviI y ambos se hallaban en la corte española en el primer cuarto del siglo, por lo que es muy probable que llegaran a influirse mutuamente. Por otro lado, Juan de la Corte trabajaba habitualmente en colaboración con otros pintores, como por ejemplo Antonio Puga, para la realización de sus retratos ecuestres, ocupándose este último de los fondos paisajísticos. ${ }^{13}$

11. Inventario de 1636. Angulo Î̃̃iguez, Pérez SÁnChez, Historia de la pintura española, p. 356.

12. Angulo Í̃̃̃guez, Pérez SÁnCHez, Historia de la pintura española, p. 350.

13. Ibidem, 351. 


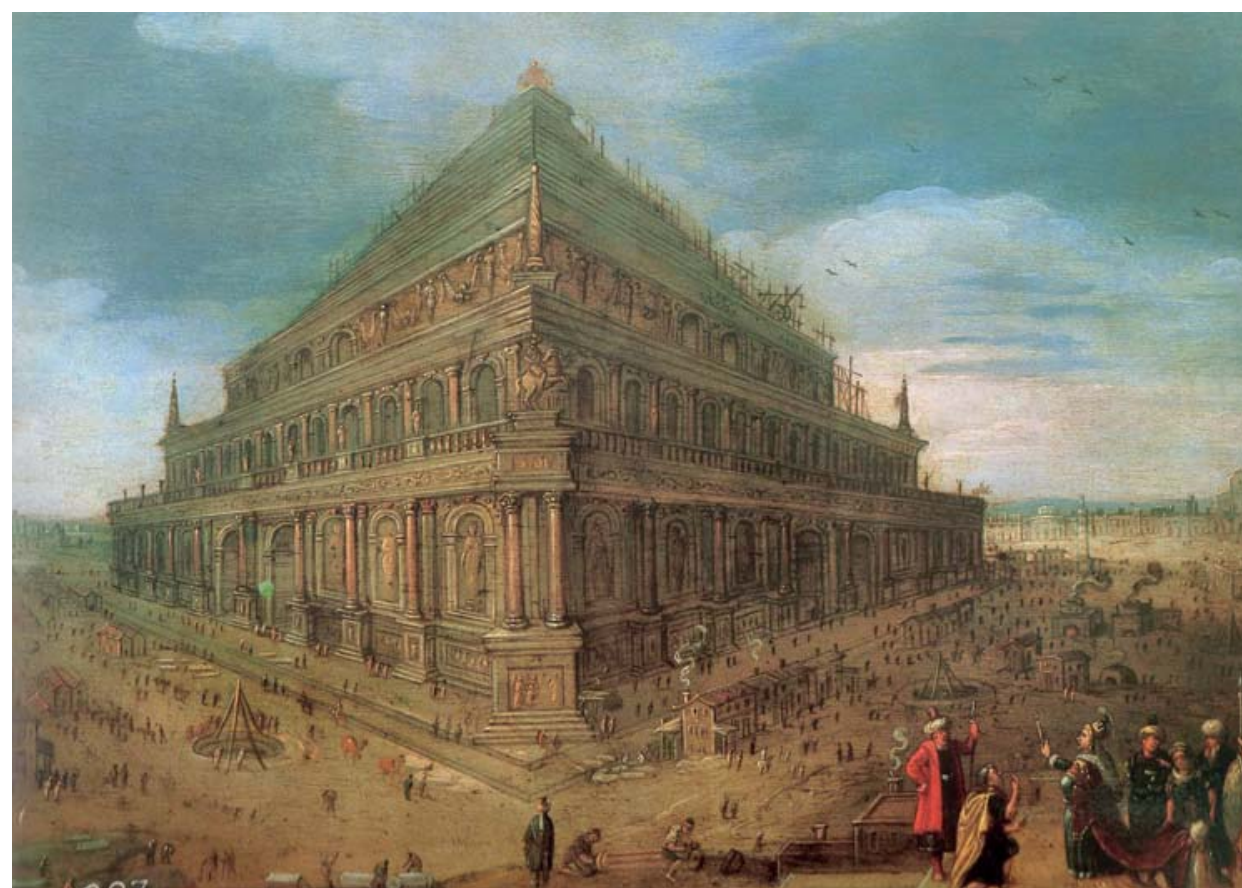

Fig. 5. Louis de CAulery, Mausoleo de Halicarnaso en la serie de las Maravillas del mundo de Caulery, siglo xviII, Palacio de Aranjuez

Juan de la Corte participó muy activamente en la decoración del Palacio del Buen Retiro con la confección de numerosas series pictóricas, de modo que se puede afirmar que fue uno de los principales artistas que contribuyeron en su ornamentación, aunque sus obras no fueran especialmente apreciadas por su calidad. Uno de los cuadros más importantes que se le atribuyen es el Socorro de Valenza del Po por don Carlos Colonna, realizado en colaboración con Velázquez, quien pintó la cabeza del retrato según la Testamentaría de 1701 (n. $\left.{ }^{\circ} 275\right)$. Esta pintura ocupaba una sala que recibía el mismo nombre, por lo que se considera un cuadro que tendría cierta relevancia. ${ }^{14}$ Además, dado el perfil del pintor como ejecutor de series de diversas temáticas a precios razonables, se le encargaron muchas como parte de la decoración del Buen Retiro. Se han computado más de cincuenta cuadros según los diferentes inventarios. ${ }^{15}$ Por ejemplo, en el Inventario de 1701 figuran en este palacio tres lienzos con historias del Antiguo Testamento; varios lienzos con paisajes; varias vistas de edificios y de fiestas citados en el mismo inventario: Perspectiva y jardines, Vista del sitio de Aranjuez, Juego de cañas en la Plaza de Madrid, Encierro de Toros en la teba; numerosos cuadros de tema mitológico como

14. Úbeda de los CoBos, «La decoración pictórica del Palacio del Buen Retiro», p. 25.

15. MARtínez Ripoll, «Juan de la Corte», p. 312. 


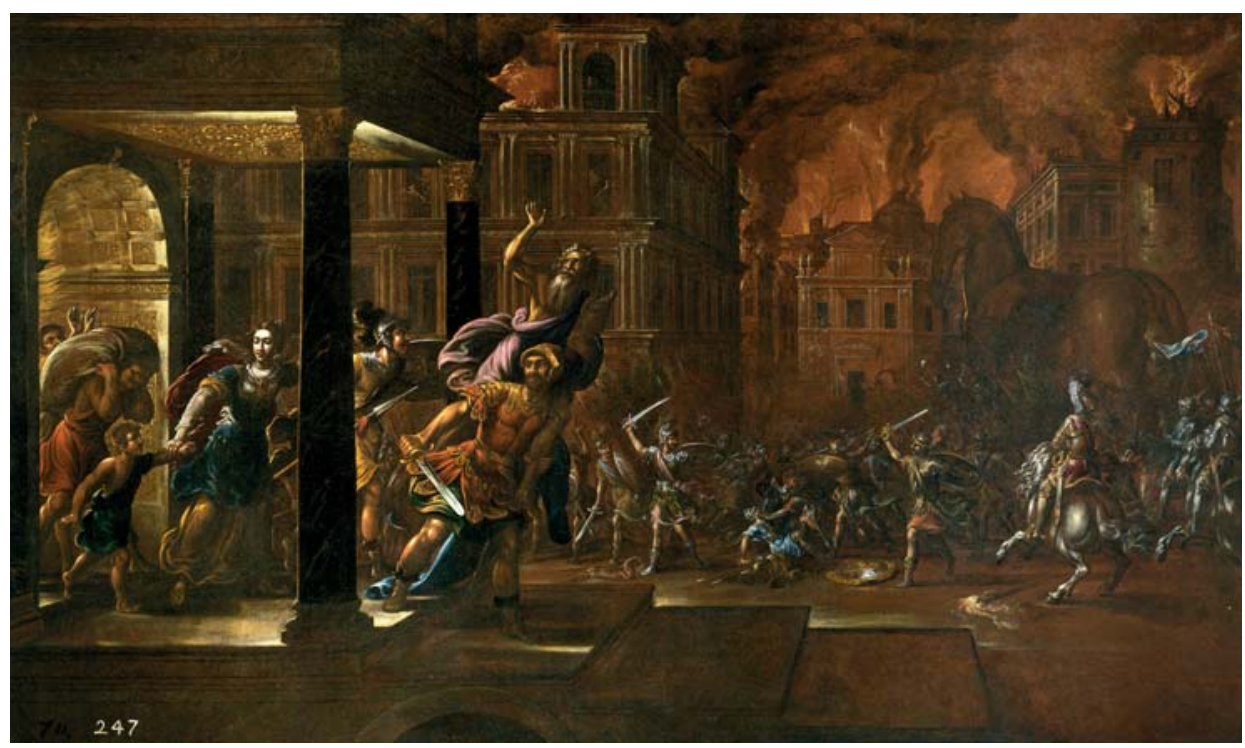

Fig. 6. JuAn DE LA CoRTe, El incendio de Troya. Primera mitad siglo XVII, Museo del Prado, Madrid

historias de las Metamorfosis de Ovidio e Historias de Troya [Fig. 6]; varios lienzos de temas bíblicos centrados en historias de monarcas, como Baltasar, David o Salomón; otros en santas eremitas, como la Magdalena y santa María Egipcíaca; y otros muchos cuadros con Historias de Carlos V, diversas batallas y hasta un Incendio del Escorial el año de 1633 (Museo de la Escuela de Arquitectura). ${ }^{16}$

Aunque tras el análisis pormenorizado de la pintura la atribución a Juan de la Corte planteada por el profesor Martínez Ripoll nos parece acertada, no podemos descartar totalmente otra posible autoría. Francisco Gutiérrez (c. 1616-1670) fue un pintor madrileño especializado en perspectivas arquitectónicas fantásticas en las que incluía historias bíblicas y mitológicas. Sabemos que estuvo próximo a Velázquez y seguramente vinculado a Juan de la Corte, ${ }^{17}$ con el que quizá se formaría, pues hacia el año 1630 en que empezó su aprendizaje en la corte no había otro artista capaz de facilitarle enseñanzas sobre este tipo de perspectivas, en las que ambos incluyeron escenas temáticamente coincidentes. Un ejemplo de su capacidad de recrear escenografías arquitectónicas pretendidamente históricas es la obra que se le ha atribuido, Reconstrucción del Templo de Salomón (Proyecto de un Templo) en la Colección de la Universidad de Zaragoza, que perteneció a las Colecciones Reales. No obstante, la autoría no es segura, pues el lienzo se ha datado en 1610, y

16. Diego Angulo Í̃̃iguez, Alfonso E. Pérez Sánchez, Historia de la pintura española. Escuela madrileña del primer tercio del siglo XVII, Instituto Diego Velázquez, Madrid, 1969, pp. 354-368.

17. Angulo Í̃̃iguez, Pérez SÁnchez, Historia de la pintura española, 1983, pp. 69-74. 
de ser la fecha correcta no pudo realizarlo Gutiérrez, aunque sí el propio Juan de la Corte. En cualquier caso, hacia 1635-1640 Gutiérrez tendría ya la madurez suficiente para componer un lienzo como el de la colección Pollock House, más próximo al estilo de Juan de la Corte que a los lienzos que realizaría en su madurez, mucho más complejos arquitectónica y compositivamente, e inspirados en los grabados de Hans Vredeman de Vries. ${ }^{18}$ En sus pinturas son casi obsesivas las referencias al Templo de Salomón. Gutiérrez realizaría en la década de los sesenta del siglo XviI lienzos con impresionantes vistas arquitectónicas, siendo un exponente la serie de la colegiata de Villagarcía de Campos. Este tipo de composiciones de grandiosas perspectivas arquitectónicas enmascarando asuntos bíblicos, mitológicos e históricos son propias de la escuela madrileña del siglo XVII, siendo otros ejemplos la producción de artistas como Roque Ponce o Enrique Giner, o el ya mencionado Louis de Caullery.

\section{El baldaquino del lienzo de Pollock House y el Buen Retiro como TEMPlo de SALOMÓN}

Abordemos en este momento la cuarta de las incógnitas que presenta el lienzo de la colección Pollock House. Uno de los elementos más interesantes de la pintura es la columnata-baldaquino que preside la perspectiva del lienzo, dejando como fondo el patio con su configuración arquitectónica y los pequeños jardines geométricos a ambos lados. Según Martínez Ripoll esta estructura sería algún tipo de fastuoso decorado que tuvo que ser desmontado en 1642 para la colocación de la escultura de Tacca, sin añadir ninguna otra información al respecto y como ya hemos dicho, confundiéndose de jardín. ${ }^{19}$ Destacan las enormes basas bulbosas, decoradas con roleos vegetales y tenantes, que soportan doce columnas salomónicas, características de Juan de la Corte. La estructura cuadrada se cierra con tres pórticos conformados por tres arquerías, mientras el cuarto queda oculto tras el espectador. Llama la atención también el artesonado de la cubierta de madera. Desde luego el estilo arquitectónico en nada se asemeja al de los Sitios Reales de los Austrias. La atribución de esta fantasía arquitectónica a Juan de la Corte cobra fuerza en los pequeños detalles de la columnata-baldaquino salomónica. Así por ejemplo, en el lienzo de la Destrucción de Troya encontramos columnas muy similares, con el primer tercio del fuste estriado y el resto con decoración de putti cabalgando sobre enramadas. También es idéntica la característica utilización de hojas de acanto para dividir las distintas secciones del fuste, o el friso del artesonado,

18. Francisco Gutiérrez, como Juan de la Corte, sigue siendo un artista poco estudiado y los textos de referencia son ya de hace tres décadas: ENRIQUE VALDIVIESO, «Francisco Gutiérrez, pintor de perspectivas», Boletín del Museo del Prado, n. ${ }^{\circ}$ II, pp. 175-180 y EnRique VAldivieso, «Nuevos datos y obras de Francisco Gutiérrez», Boletín del Prado, n. ${ }^{\circ}$ XIII, pp. 7-10.

19. Martínez Ripoll, «Juan de la Corte», p. 320. 


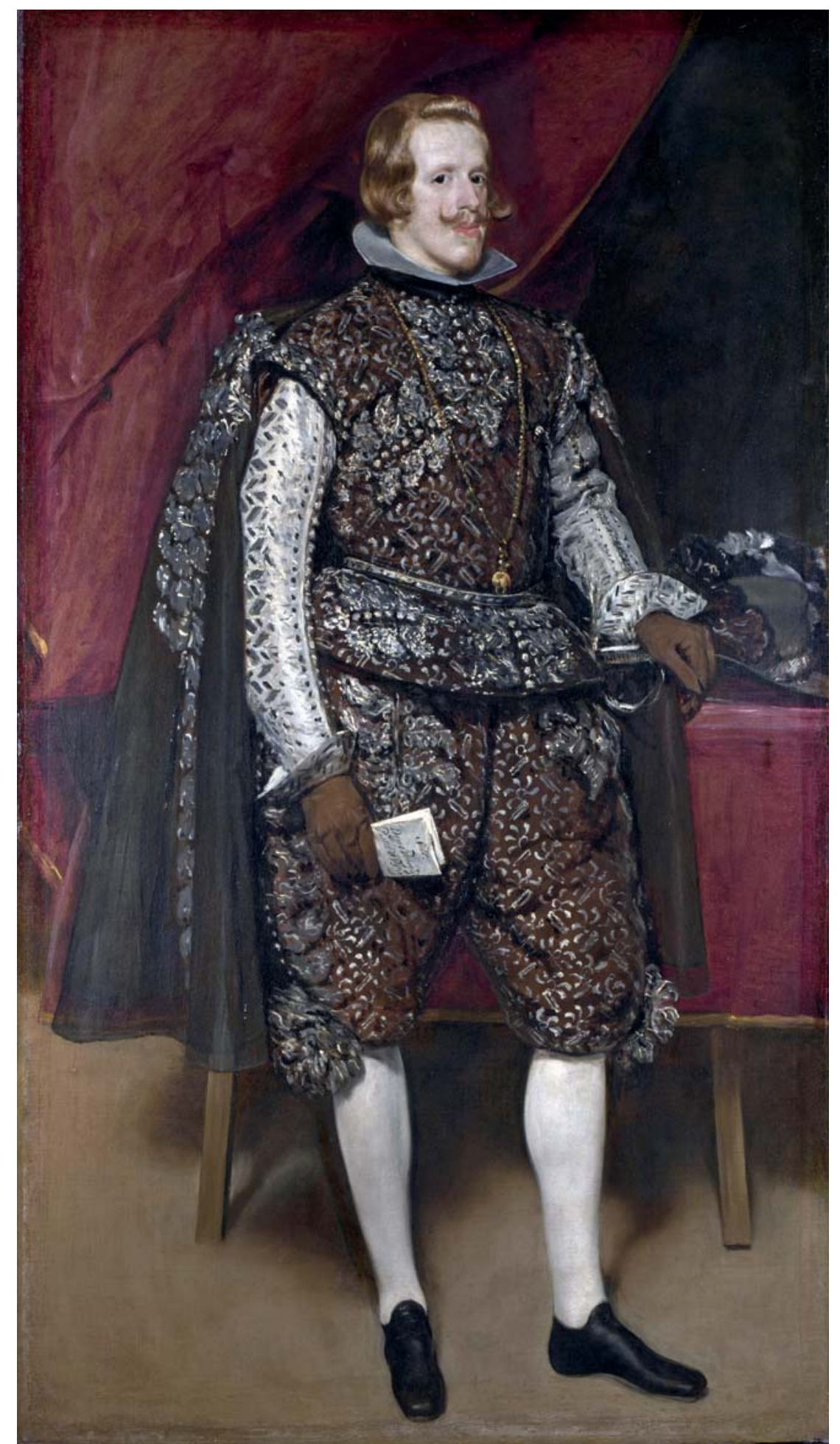

Fig. 7. VelÁzQUEZ, Felipe IV de castaño y plata, hacia 1631-1632, National Gallery, Londres 
con decoración de roleos vegetales. Perspectivas centralizadas con estructuras arquitectónicas del mismo estilo y columnatas salomónicas las encontramos también en otros lienzos suyos, como el Encuentro de París y Elena (colección particular, Murcia) y la Circuncisión de Cristo (Universidad de Murcia).

El canon alargado de sus figuras, con cabezas pequeñas, es también otra característica formal coincidente con la obra de Juan de la Corte, así como la poca pericia en la representación de las expresiones de los rostros. No obstante, la fisonomía en este caso es correcta y en ese sentido no es de extrañar la tradicional filiación del cuadro a la escuela velazqueña, pues las figuras del valido y su esposa y de los monarcas remiten sin duda a los retratos de Velázquez. El conde-duque muestra el corte de pelo y barba propios del retrato de 1623 de la Colección Várez-Fisa o el de en torno a 1625-1626 en The Hispanic Society of America, Nueva York. La figura del monarca evoca el retrato de castaño y plata de Velázquez de la National Gallery de Londres, también alrededor de 16311632 [Fig. 7]. La reina está representada de manera similar, aunque notablemente simplificada, en el retrato ecuestre de Velázquez para el Salón de Reinos, sobre 1628-1635. Incluso por ejemplo, Juan de la Corte ha conservado el gesto de la condesa de Olivares en el supuesto retrato de Velázquez de hacia 1635, conocido como Retrato de dama (Gemäldegalerie, Berlín), de apoyar la mano en una silla, para mostrar en su lienzo un gesto de protección hacia la hija [Fig. 8].

Destaca precisamente el movimiento de los personajes en su paso por la columnata, como si estuvieran atravesándola, dirigidos por el conde-duque de Olivares y cerrando la comitiva su esposa y su hija. Se trata de una cadencia de baile, muy característica de la escuela de Amberes ya citada de grandes representaciones arquitectónicas y paisajísticas de carácter galante. Quizá el hecho de que sea Olivares quien dirige los pasos de los monarcas y del príncipe pueda dar pistas sobre el encargo de la obra, pues se insinúa que el valido está mostrando al monarca la magnificencia de su nuevo palacio y patio. Como explicaron Jonathan Brown y J. H. Elliott, cuando Olivares decidió emprender la construcción de un gran palacio de recreo para Felipe IV, existían diversas alternativas que podían usarse como núcleo, las casas reales de Aranjuez -algo distante de la capital- y el Pardo -mantenido como coto de caza-, y un espacio natural privilegiado muy próximo a Madrid, la Casa de Campo -aunque vinculado al caído duque de Lerma. Pero la circunstancia de que el príncipe Baltasar Carlos tuviera que recibir en la iglesia del monasterio de San Jerónimo el juramento de lealtad de la nobleza y las Cortes de Castilla -ceremonia que tuvo lugar el 7 de marzo de 1632-, y el nombramiento como alcaide del Cuarto Real de San Jerónimo que Olivares recibió el 10 de julio de 1630, convencieron a este último de la conveniencia de ubicar el nuevo palacio en este lugar. ${ }^{20}$ Por lo tanto, en sus inicios el Buen Retiro no solo es concebido como escenario de la corte de Felipe IV, sino también como espacio privilegiado de la vida

20. Jonathan Brown y J. H. Elliott, Un palacio para el rey. El Buen Retiro y la corte de Felipe IV, Alianza, Madrid, 1981, p. 59 


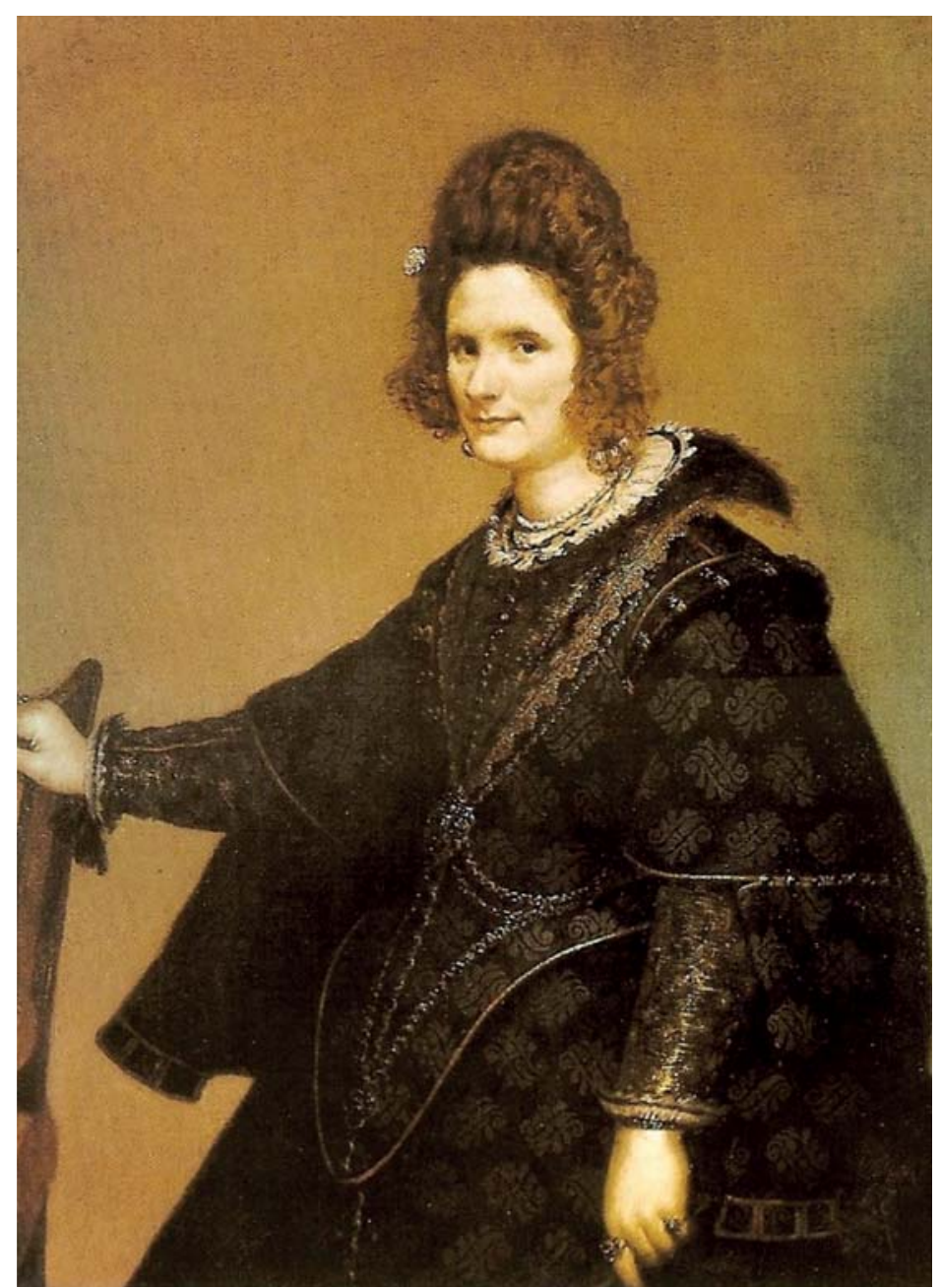

Fig. 8. VelázQuez, Retrato de dama, hacia 1635, Gemäldegalerie, Berlín

política del príncipe heredero y como manifestación asimismo del poder del valido, idea que está implícita en la pintura de Pollock House, pues todos los actores, junto con sus consortes, aparecen representados jerárquicamente en los diversos intercolumnios del colosal baldaquino salomónico que preside el gran patio. Respecto al enano, recordemos que el propio Velázquez pintó uno acompañando a Baltasar Carlos precisamente en el retrato que conmemoró la ceremonia de la jura de fidelidad celebrada en el Buen Retiro, El príncipe Baltasar Carlos y un enano (Museum of Fine Arts, Boston) [Fig. 9]. ${ }^{21}$

21. Sobre la presencia del enano véase: FERnANDo MARÍAS, «La representación del heredero: la imagen del Príncipe de Asturias», en Heinz-Dieter Heimann, Silke Knippschild, Víctor Mínguez (eds.), Ceremoniales, ritos y representación del poder, Universitat Jaume I, Castellón, 2004, pp. 129-130. 


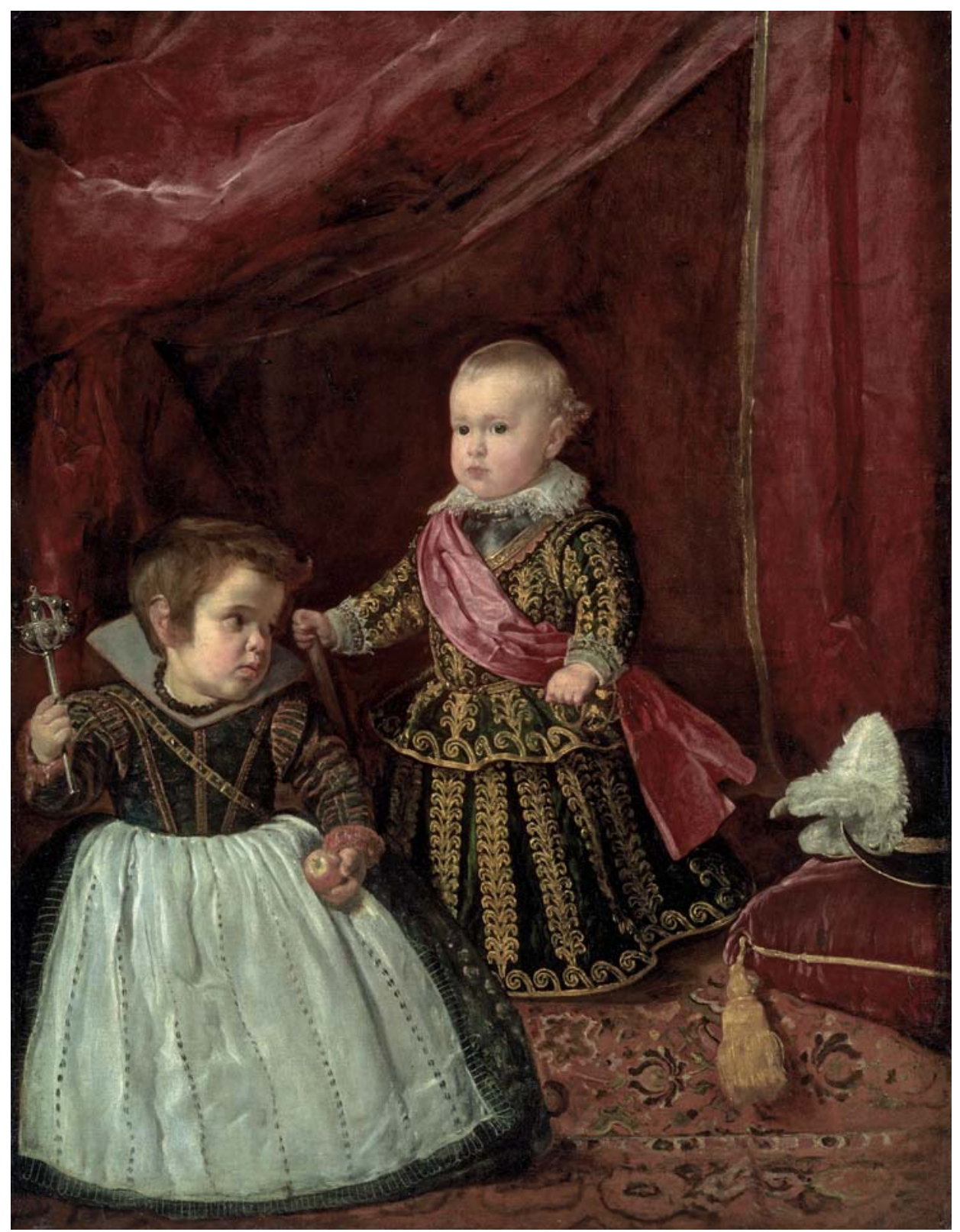

Fig. 9. VelázQuez, El príncipe Baltasar Carlos y un enano, Museum of Fine Arts, Boston

Pero el Cuarto Real preexistente, construido por Juan Bautista de Toledo durante el reinado de Felipe II, apenas eran unas pocas dependencias. Por lo tanto, cuando Juan Bautista Crescenzi, ayudado por el maestro de obra Alonso Carbonel, ambos a las órdenes de Olivares, empieza a imaginar el nuevo palacio y a diseñar el proyecto de ampliación, puede fantasear todo lo que quiere. De 
hecho, en 1635, fecha en torno a la cual como hemos dicho Juan de la Corte debió pintar el lienzo que nos ocupa, y aunque entonces el Buen Retiro ya estaba construido en su mayor parte, en muchos aspectos seguía siendo más un proyecto ambicioso que una realidad. Las obras emprendidas desde 1630 habían sido modestas, si bien en 1633 ya se hallaban en pie varios edificios, y se había decidido ya construir una gran plaza para fiestas que articulase el conjunto. Es ese año cuando el Buen Retiro pasará de ser concebido como una ampliación del antiguo Cuarto Real a un nuevo y gran palacio en toda regla. Brown y Elliott opinan que la conversión del inicial pequeño retiro suburbano en una grandiosa residencia real que se produce en 1633 se debió entre otras razones a las críticas que hasta ese momento había recibido el conjunto, por considerarse indigno de un monarca, menor incluso en tamaño al vecino palacio del duque de Lerma. ${ }^{22}$ La modificación de los planes iniciales es muy rápida, el edificio se construye con presteza, y los días 5 y 6 de diciembre de ese año se inaugura lo que ya está concluido.

El gran lienzo de Pollock House es la materialización de ese sueño, un palacio que es imaginado grande, bello, armonioso, fruto de la más perfecta arquitectura, que se desea se convierta rápidamente en el teatro cortesano desde el que Felipe IV y el conde-duque gobernarán el imperio que heredará con el tiempo el príncipe Baltasar Carlos. Los alabarderos del fondo y el caballero y las damas que pasean por el jardín insuflan vida a este escenario de poder cuya construcción tanto madrileños, como adversarios del privado y embajadores de otros países seguían con gran interés. Precisamente, las críticas que el edificio recibió por su falta de magnificencia y su estilo monástico, ${ }^{23}$ pudieron haber sido el acicate para que alguien, quizá el propio Olivares, encargase a Juan de la Corte, si finalmente se confirma la autoría del lienzo, la realización de esta pintura que recrea, no lo que se hubiera querido que fuera el Buen Retiro, sino lo que todavía se pretendía que fuese, pues poco después, en 1637, el valido solicitó a un arquitecto veneciano un proyecto para revestir de mármol italiano las fachadas del palacio, proyecto que será inviable por su elevado coste. ${ }^{24}$

Un elemento más nos puede ayudar a interpretar este lienzo y su intención. Durante la fiesta del Corpus Christi de 1634 se estrena en el Estanque Grande el auto sacramental alegórico de Calderón de la Barca, El nuevo palacio del Retiro. El dramaturgo realizó en este texto una compleja argumentación político-teológica sobre el sentido simbólico del Buen Retiro - para compensar precisamente las mencionadas críticas al edificio-, el gobierno bajo el sistema del valimiento, la función del ceremonial cortesano, ${ }^{25} \mathrm{y}$ la comparación entre el

22. BRown y ELLIOTt, Un palacio para el rey..., p. 66.

23. Ibidem, 74 .

24. Ibidem, 54.

25. Adolfo Carrasco Martínez, «'Rey por ceremonia’: ceremonial y lucha política en la privanza de Olivares», en Giuseppe Galasso, José Vicente Quirarte, José Luis Colomer (dir.), Fiesta y ceremonia en la corte virreinal de Nápoles (siglos XVI y XVII), CEEH, Madrid, 2013, p. 61. 


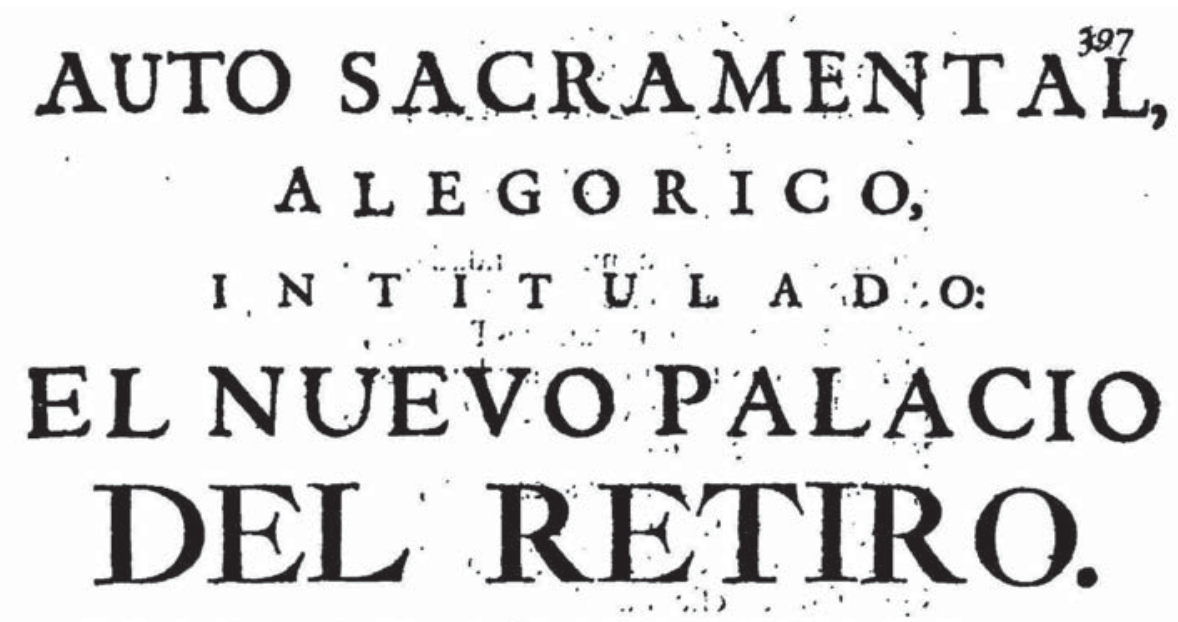

DE DON PEDRO CALDERON DE LA BARCA.

P ERSO N A S.

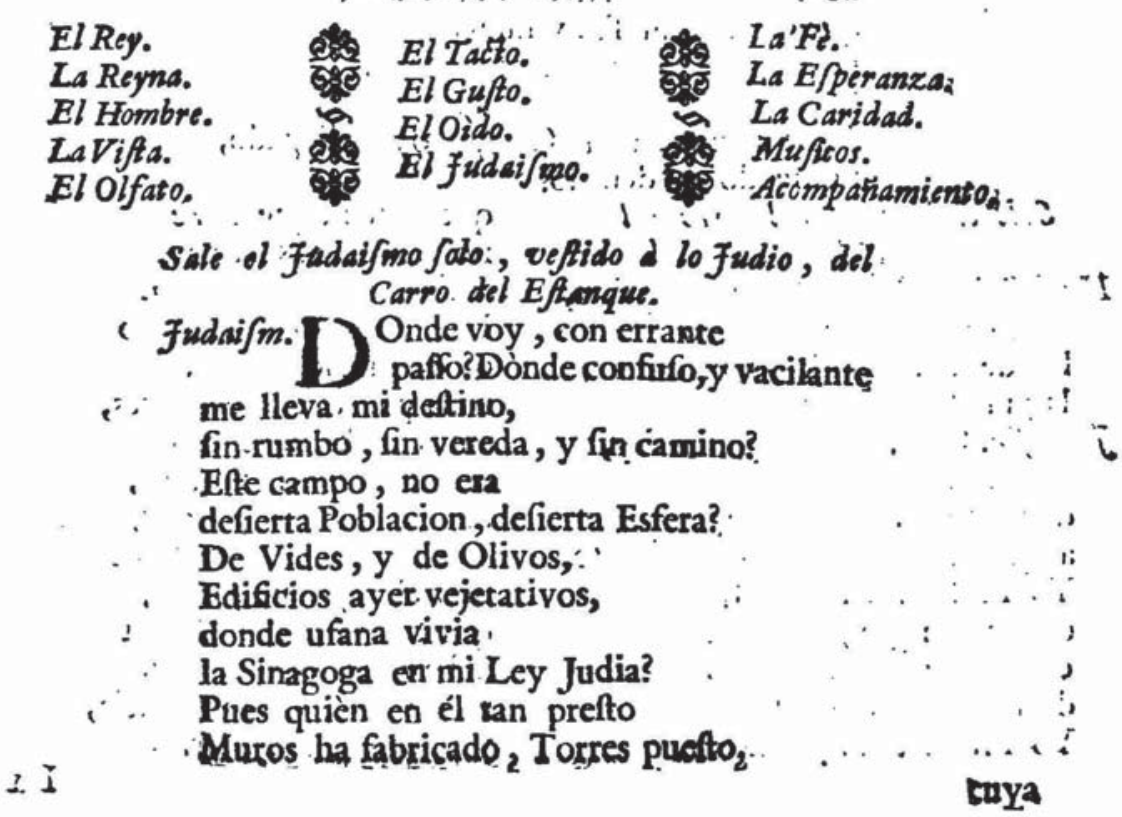

Fig. 10. Portada del auto sacramental de CALDerón de la BARCA, El nuevo Palacio del Retiro

rey y la divinidad, dada la ocasión de su estreno. El auto había sido un encargo del propio Olivares. Lo interesante de él es que el palacio era presentado como el Templo de Salomón, sustentado sobre doce columnas y con doce puertas, 
constituyendo la última maravilla construida, hasta convertirse en la propia Jerusalén celestial:

Su fábrica dorada / en doce piedras se miró fundada. / Doce puertas abiertas están; al aquilón miran tres puertas, al austro tres se rompen blandamente, / tres al ocaso y tres hacia el oriente, / y todas doce iguales, / guarnecidas de cándidos cristales / en quien mi Ley conoce / doce vislumbres de mis tribus doce. / ¿Qué fábrica ésta ha sido? / ¿Para quién, para quién se ha prevenido / esta casa, este templo, / última maravilla sin ejemplo? ${ }^{26}$

Una descripción que sin duda nos recuerda al baldaquino que cobija a la familia real y al valido en el lienzo de Pollock House. Y aunque el rey y la reina son personajes protagonistas en el auto, junto con las virtudes, los cinco sentidos y el judaísmo, otro personaje, el «Hombre», hace referencia al propio Olivares. Además, aunque no se le menciona expresamente, está siempre presente a través de numerosas alusiones y sobre todo, a través de la exaltación del gobierno en forma de privanza y de la construcción del palacio. También el heredero, el príncipe Baltasar Carlos, aparece mencionado en el auto, así como los miembros de la corte en una fingida fiesta de caballos por parejas, en la que el rey y el valido participan como iguales. Todas estos personajes y esta compleja argumentación teológica del reinado de Felipe IV y de la construcción del Buen Retiro reforzarían la idea de que el lienzo de Juan de la Corte pudo ser un encargo del propio Olivares, inspirado en este auto sacramental, en el que el valido y su familia, mostrarían a la familia real -cobijada cual arca de la Alianza- su nuevo palacio-templo de Salomón recién inaugurado. Incluso en nuestra opinión y retomando lo sugerido por otros autores, ${ }^{27}$ cabe la posibilidad de que en realidad la arquitectura representada pudiera recoger una estructura efímera construida con motivo precisamente de la celebración del mencionado Corpus de 1634 y su representación sacramental. Recordemos también cómo desde el primer momento de su construcción, numerosos panegíricos atribuyeron al Buen Retiro calificativos como «casa del sol», «Augusto nido» y una de las siete Maravillas del Mundo. ${ }^{28}$

El lienzo de Pollock House es por lo tanto un formidable testimonio del proyecto arquitectónico que anidaba en la mente del conde-duque de Olivares y sus colaboradores, un escenario palaciego monumental, plagado de resonancias simbólicas y teológicas, digno de la corte del Rey Planeta. Un testimonio

26. Pedro Calderón de la Barca, El nuevo palacio del Retiro, edición digital a partir de la publicación de A. K. Paterson, Universidad de Navarra, Kassel Reichenberger, 1998, Biblioteca Virtual Miguel de Cervantes. http://bib.cervantesvirtual.com/FichaObra.html?Ref=4142.

27. Ya hemos avanzado que Martínez Ripoll considera el baldaquino una estructura efímera sin especificar nada más, también SimAL López incluye el cuadro en su artículo titulándolo precisamente como «La familia real visita la arquitectura efímera construida en el patio del caballo guiados por el conde-duque de Olivares, 1635-1640».

28. Antonio Bonet Correa, «El palacio y los jardines del Buen Retiro», Militaria. Revista de Cultura Militar, n. ${ }^{\circ}$, p. 21. 
especialmente de la arquitectura clásica marmórea que debía recubrirlo otorgándole la verdadera grandeza, y de los amplios jardines que se dispondrán entre 1634 y 1640, y que evocan los parterres geométricos del Jardín de la Reina que se vislumbran en el lienzo más allá del baldaquino. Un escenario en definitiva que la falta de planificación previa, la urgencia, la improvisación, y la carencia de recursos económicos impedirían materializar finalmente. Pero este sueño arquitectónico es también una recreación del proyecto político que el valido imaginaba para la monarquía hispánica, basado en la unidad y el centralismo, en el cristianismo triunfante, en el que él mismo, como en la propia pintura, desempeñaría un papel relevante como arquitecto e ideólogo. 